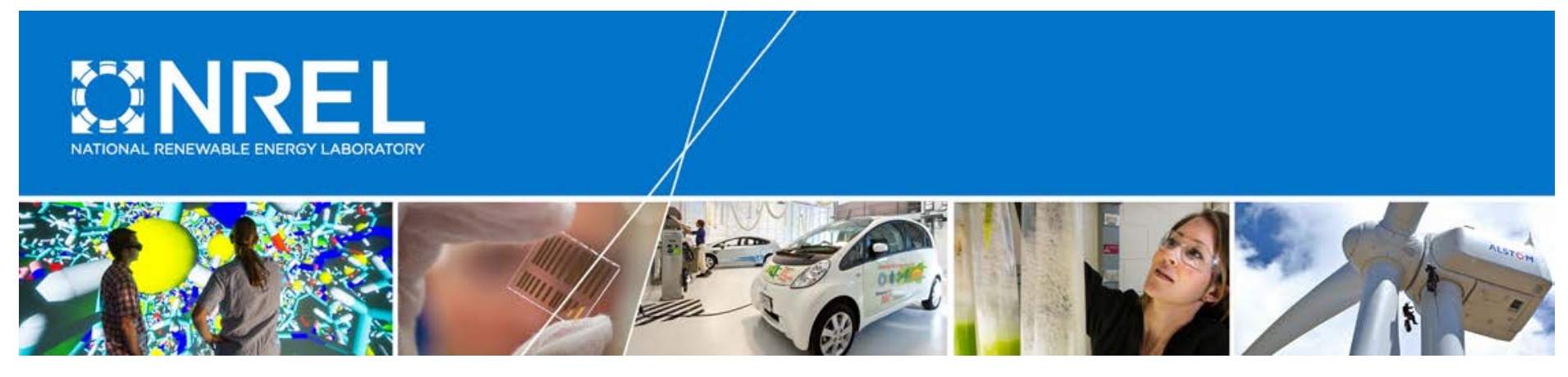

\title{
Diagnosing Model Errors in Simulations of Solar Radiation on Inclined Surfaces
}

\section{Preprint}

\author{
Yu Xie and Manajit Sengupta \\ National Renewable Energy Laboratory
}

Presented at the 43rd IEEE Photovoltaic Specialists Conference Portland, Oregon

June 5-10, 2016

(C) 2016 IEEE. Personal use of this material is permitted. Permission from IEEE must be obtained for all other uses, in any current or future media, including reprinting/republishing this material for advertising or promotional purposes, creating new collective works, for resale or redistribution to servers or lists, or reuse of any copyrighted component of this w ork in other w orks.

NREL is a national laboratory of the U.S. Department of Energy Office of Energy Efficiency \& Renewable Energy Operated by the Alliance for Sustainable Energy, LLC

This report is available at no cost from the National Renewable Energy Laboratory (NREL) at www.nrel.gov/publications.

Conference Paper

NREL/CP-5D00-66489

June 2016

Contract No. DE-AC36-08G028308 


\section{NOTICE}

The submitted manuscript has been offered by an employee of the Alliance for Sustainable Energy, LLC (Alliance), a contractor of the US Government under Contract No. DE-AC36-08GO28308. Accordingly, the US Government and Alliance retain a nonexclusive royalty-free license to publish or reproduce the published form of this contribution, or allow others to do so, for US Government purposes.

This report was prepared as an account of work sponsored by an agency of the United States government. Neither the United States government nor any agency thereof, nor any of their employees, makes any warranty, express or implied, or assumes any legal liability or responsibility for the accuracy, completeness, or usefulness of any information, apparatus, product, or process disclosed, or represents that its use would not infringe privately owned rights. Reference herein to any specific commercial product, process, or service by trade name, trademark, manufacturer, or otherwise does not necessarily constitute or imply its endorsement, recommendation, or favoring by the United States government or any agency thereof. The views and opinions of authors expressed herein do not necessarily state or reflect those of the United States government or any agency thereof.

This report is available at no cost from the National Renewable Energy Laboratory (NREL) at www.nrel.gov/publications.

Available electronically at SciTech Connect http:/www.osti.gov/scitech

Available for a processing fee to U.S. Department of Energy and its contractors, in paper, from:

U.S. Department of Energy

Office of Scientific and Technical Information

P.O. Box 62

Oak Ridge, TN 37831-0062

OSTI http://www.osti.gov

Phone: 865.576.8401

Fax: 865.576.5728

Email: reports@osti.gov

Available for sale to the public, in paper, from:

U.S. Department of Commerce National Technical Information Service 5301 Shawnee Road

Alexandria, VA 22312

NTIS http://www.ntis.gov

Phone: 800.553 .6847 or 703.605 .6000

Fax: 703.605.6900

Email: orders@ntis.gov 


\title{
Diagnosing Model Errors in Simulations of Solar Radiation on Inclined Surfaces
}

\author{
Yu Xie and Manajit Sengupta
}

\author{
National Renewable Energy Laboratory, Golden, CO, 80401, USA
}

\begin{abstract}
Transposition models have been widely used in the solar energy industry to simulate solar radiation on inclined photovoltaic solar panels. Following numerous studies comparing the performance of transposition models, this paper aims to understand the quantitative uncertainty in current state-of-the-art transposition models and the sources leading to the uncertainty. Our results show significant differences between two highly used isotropic transposition models, with one substantially underestimating the diffuse plane-of-array irradiances when diffuse radiation is perfectly isotropic. In the empirical transposition models, the selection of empirical coefficients and land surface albedo can both result in uncertainty in the output. This study can be used as a guide for the future development of physics-based transposition models.

Index Terms - solar energy, photovoltaic systems
\end{abstract}

\section{INTRODUCTION}

The increasing use of solar energy as an alternative to conventional energy sources has boosted the demand to precisely measure solar radiation at the surface. Although solar radiation data from surface measurements [1] or satellite retrievals $[2,3]$ are routinely available on horizontal surfaces, transposition models are used to convert the horizontal values to plane-of-array (POA) irradiances on inclined surfaces [4-8].

Three sources contribute to POA irradiance on an inclined surface: direct sky radiation, diffuse sky radiation, and reflected radiation from the land surface. Current transposition models simulate the contribution from diffuse sky radiation by following either empirical equations correlating it to diffuse horizontal irradiance (DHI) (hereafter referred to as the empirical model) $[4,6]$ or by assuming that the diffuse radiances are is otropic over the sky dome (hereafter referred to as the isotropic model) [7, 8]. Compared to empirical models, is otropic models underestimate the strong forward scattering by clouds or aerosols [9-12]; thus, they are likely to underestimate POA irradiance on 1- or 2-axis photovoltaic (PV) solar panels. However, the accuracy of empirical models may vary with localized atmospheric and land surface conditions. Moreover, rapid variations of meteorological or land surface conditions-e.g., a sudden snowfall-may lead to nonignorable bias in empirical models that rely on long-term observations.

The uncertainties related to isotropic and empirical models can be substantially reduced by using a physics-based model that employs retrieved atmospheric and land surface properties to precisely simulate diffuse radiances in all possible directions and integrate them to form POA irradiance. Physics-based models have an added advantage because they can benefit from the rapid development of remote sensing technologies. For example, the expansion of spectral channels that have better temporal and spatial resolution, such as the future Geostationary Operational Environmental Satellite-R (GOES-R), will lead to remarkable improvements in aerosol and cloud products.

To evaluate the performance of the potential physics-based model, it is first important to quantitatively understand the uncertainties in the state-of-the-art transposition models. Despite numerous studies on comparisons between surface measurements and transposition models, the sources affecting model accuracy have not been fully explored. The purpose of this paper is to evaluate the accuracy of an isotropic and an empirical model using surface measurements at the National Renewable Energy Laboratory (NREL) Solar Radiation Research Laboratory (SRRL). This paper investigates the reasons for uncertainty in these models and serves as a guide for the development of physics-based models.

\section{TRANSPOSITION MODELS}

Almost all transposition models express POA irradiance on an inclined surface by:

$$
P O A I=P O A I_{d}+P O A I_{u, s k y}+P O A I_{u, \text { ground }}
$$

where $P O A I_{d}, P O A I_{u, s k y}$, and $P O A I_{u, \text { ground }}$ represent POA irradiances from direct solar radiation, diffuse sky radiation, and solar radiation reflected by the land surface that reaches the PV panel, respectively.

$P O A I_{d}$ can be given by the partitioning of direct solar radiation in the normal direction of the PV panel, as follows:

$$
\mathrm{POAI}_{d}=\mathrm{DNI} \cos \theta^{\prime}
$$

where $\theta^{\prime}$ is the angle between direct solar radiation and the normal direction of the PV panel. The value of $\theta^{\prime}$ can be solved by rotating a horizontal plane to an inclined PV plane:

$$
\cos \theta^{\prime}=\cos \beta \cos \theta+\sin \beta \sin \theta \cos \varphi
$$

where $\theta$ is solar zenith angle, $\varphi$ is the relative azimuth angle, and $\beta$ is the tilt angle of the PV panel. 


\section{A. Isotropic Model}

The contribution of diffuse POA irradiance from the sky, $P O A I_{u, s k y}$, can be given by the integration of radiances in the perpendicular direction to the tilted PV panel:

$$
P O A I_{u, s k y}=\int_{0}^{2 \pi} \int_{0}^{\Theta_{1}} I \cos \theta^{\prime} \sin \theta d \theta d \varphi
$$

where $\mathrm{I}$ is the radiance, and $\Theta_{1}$ denotes the upper limit of $\theta$. Because the contribution of radiance to the POA should be positive, the integration in Eq. (3) must satisfy:

$$
\cos \theta^{\prime}=\cos \beta \cos \Theta_{1}+\sin \beta \sin \Theta_{1} \cos \varphi \geq 0
$$

or:

$$
\Theta_{1}=\left\{\begin{array}{cc}
\frac{\pi}{2} \text { when } 0<\varphi \leq \frac{\pi}{2} & \text { or } \frac{3 \pi}{4} \leq \varphi<2 \pi \\
\frac{\pi}{2}-\tan ^{-1}(-\tan \beta \cos \varphi) & \text { when } \frac{\pi}{2}<\varphi<\frac{3 \pi}{4}
\end{array}\right.
$$

Liu and Jordan [7] (hereafter referred to as LJ1961) analytically solved Eq.(3) with isotropic radiances, as follows [8]:

$$
P O A I_{u, s k y}=D H I \frac{1+\cos \beta}{2}
$$

This has been widely used to represent the solution from an is otropic model.

Badescu [8] (hereafter referred to as BA2002) suggested that LJ1963 is a solution of the isotropic model on the bas is of a two-dimensional geometry. He then derived the solution of Eq.(3) following the three-dimensional geometry. From his derivation, the diffuse POA irradiance from the sky is:

$$
P O A I_{u, s k y}=D H I \frac{3+\cos 2 \beta}{4}
$$

\section{B. Empirical Models}

Compared to is otropic models, empirical models are based on regression functions relating long-term observations of POA irradiance to DHI at selected local stations. A well-known empirical model was developed by Perez et al. [4] wherein is otropic diffuse, circumsolar, and horizon brightening radiation were considered with comprehensive sets of coefficients determined from various climatic environments. Details about the Perez model (hereafter referred to as PEREZ) are not restated here because they are described in [4].

\section{Surface Reflection Models}

Following Eq.(3), the contribution from reflected solar radiation by land surface can be given by:

$$
P O A I_{u, \text { ground }}=\int_{0}^{2 \pi} \int_{0}^{\Theta_{2}} \frac{G H I \sigma}{\pi} \cos \theta^{\prime} \sin \theta d \theta d \varphi
$$

where $\Theta_{2}$ is determined by:

$$
\cos \beta \cos \Theta_{2}-\sin \beta \sin \Theta_{2} \cos \varphi \geq 0
$$

LJ1961 provided the analytical solution of Eq.(6) as:

$$
P O A I_{u, \text { ground }}=G H \sigma \frac{1-\cos \beta}{2}
$$

where $\sigma$ is land surface albedo.

Similar to the diffuse POA irradiance from the sky, a different solution to Eq.(6) was provided by BA2002 as follows:

$$
P O A I_{u, \text { ground }}=G H I \sigma \frac{1-\cos 2 \beta}{4}
$$

\section{RESULT S}

To evaluate the isotropic models, we model perfectly isotropic radiances by assuming $\mathrm{I}$ as a function of $\varphi=0,1$, $2, \ldots, 360^{\circ}$ and $\mu=0,0.01,0.02, \ldots, 1.0$, where $\mu$ is the cosine value of $\theta$. We then use a computer model to numerically compute the integrations in Eqs.(3 and 6). Fig. 1 shows a comparis on of the diffuse POA irradiances from LJ1963, BA2002, and the computer model when $\sigma=0.2$ and $\sigma=0.8$. As shown, LJ1963 exactly matches the computer model for all surface conditions; however, the computer model suggests that BA2002 substantially underestimates the diffuse POA irradiance. The underestimation becomes less significant for higher surface albedo, as shown in Fig. 1(b).
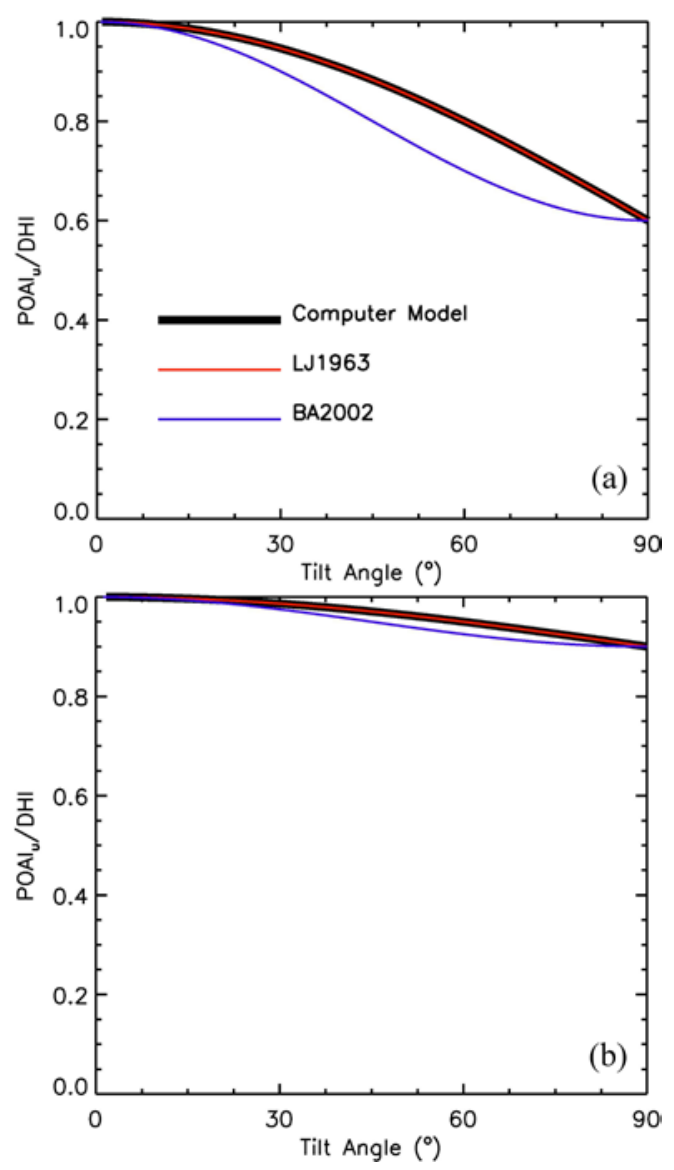

Fig. 1. $P O A I_{u} / D H I$ for (a) $\sigma=0.2$ and (b) $\sigma=0.8$ simulated by LJ1963 and BA2002 and a computer model based on Eqs.(3 and 6). 
To quantitatively understand the difference between transposition models and surface observations, we investigate 1-minute global horizontal irradiance, direct normal irradiance, DHI, and surface albedo measurements. The methods in LJ1961 and PEREZ are combined with the surface measurements to simulate the POA irradiance. The simulations are then compared to the POA irradiance by using a Kipp and Zonen CM 11 Pyranometer (CMP 11) and IMT solar reference cell (IMT) on a 1-axis tracker located at NREL.
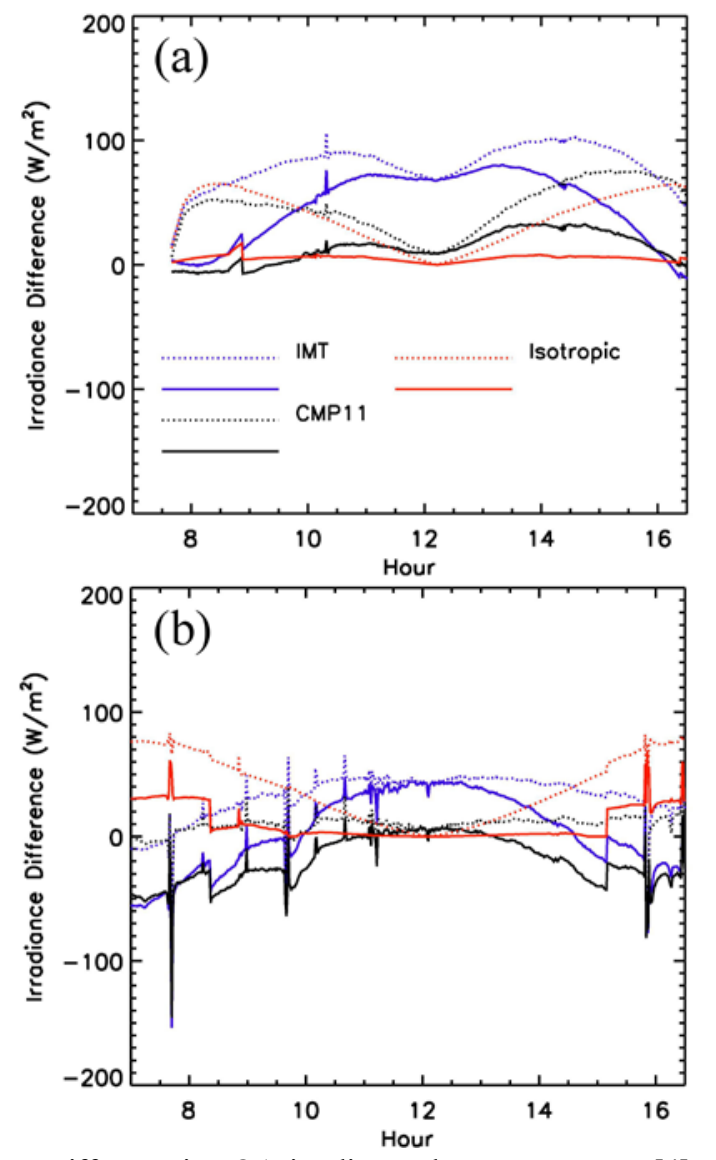

Fig. 2. Difference in POA irradiances between PEREZ [4] and the measurements and simulations from [7] on (a) 1/22/2015 (winter) and (b) $7 / 22 / 2015$ (summer). The dotted lines represent the PEREZ simulation [4], with the "France 1988" model, whereas the solid line represents the PEREZ simulations with the "Albuquerque 1988" model.

Fig. 2 shows the difference in POA irradiances between PEREZ [4] and the measurements and simulations from [7] on 1/22/2015 (a winter clear-sky day) and 7/30/2015 (a summer clear-sky day). PEREZ has 11 sets of coefficients based on measurements from various climatic environments. From the results of Fig. 2, we select "France 1988" (dotted lines) and "Albuquerque 1988" (solid lines) for PEREZ. These two coefficients were chosen to represent the full range of performance in the winter simulation. It can be found that PEREZ has better agreement to the CMP 11 measurements than those from IMT both in summer and winter. Compared to CMP 11 , on $1 / 22 / 2015$ the absolute percent errors of PEREZ associated with "France 1988" and "Albuquerque 1988" are $6.72 \%$ and $2.24 \%$, respectively. On $7 / 30 / 2015$, the absolute perfect errors for PEREZ associated with "France 1988" and "Albuquerque 1988" are $1.39 \%$ and $2.48 \%$, respectively. This indicates that different sets of coefficients from PEREZ may introduce significantly different errors. Computing POA irradiance though PEREZ with appropriate coefficients is found to perform better than the isotropic models especially under cloudy skies [13]. Accurate coefficients for PEREZ are difficult to determine because they vary with time. This is shown by comparing Fig. 2(a) to Fig. (b), wherein the "France 1988" model performs better in summer than the "Albuquerque 1988" model, and the reverse happens in winter.
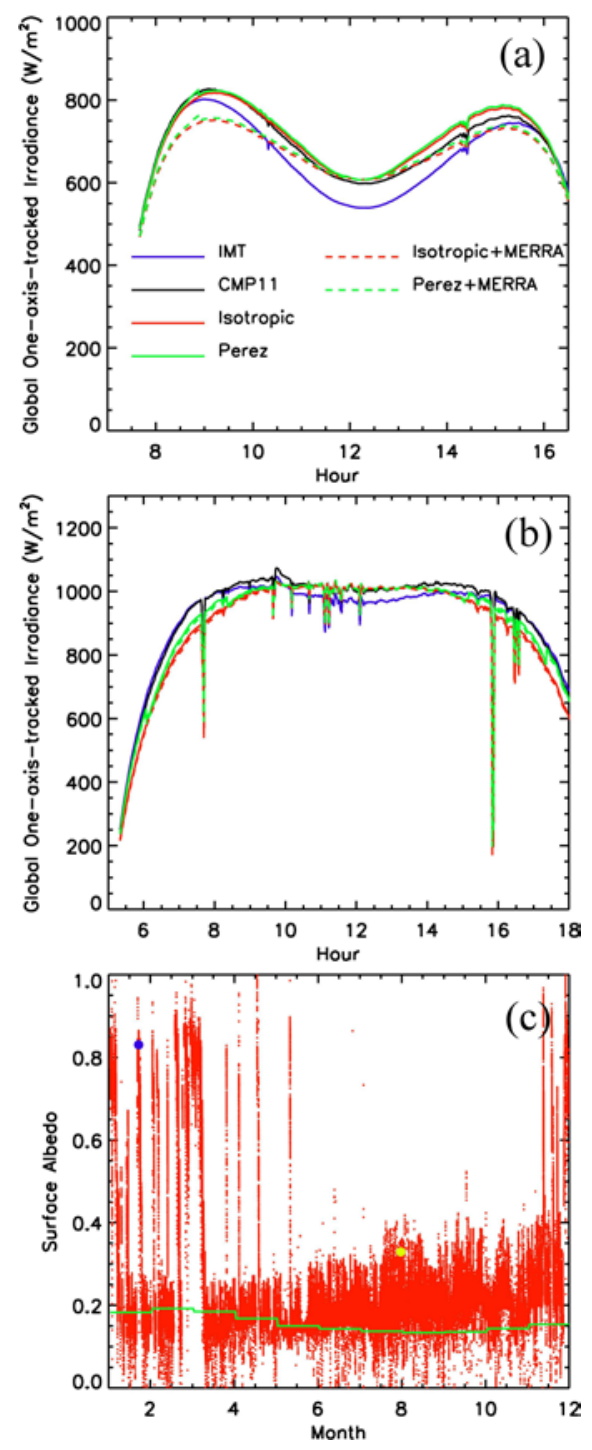

Fig. 3. POA irradiances from the measurements and model simulations on (a) 1/22/2015 and (b) 7/22/2015; and (c) surface albedo from surface measurements (red dots) and MERRA data (green lines). The blue and yellow dots represent measured surface albedos on $1 / 22 / 2015$ and $7 / 22 / 2015$, respectively. 
Fig. 3(a) and Fig. 3(b) compare the measurements and model simulations of 1-axis POA irradiances. The solid lines associated with LJ1961 and PEREZ are simulations using surface albedo measurements at NREL. The dashed lines are those from surface albedo based on a climatology using the National Aeronautics and Space Administration's ModernERA Retrospective Analysis for Research and Applications (MERRA) data [14]. Fig. 3(c) shows the surface albedo from the measurements (red dots) and MERRA data (green lines), and the blue and yellow dots represent the measurements on $1 / 22 / 2015$ (winter) and 7/30/2015 (summer), respectively. It can be concluded from Fig. 3 that surface albedo significantly impacts the estimation of POA irradiance. The uncertainty in POA irradiance is much greater in winter than summer due to the uncertainty in surface albedo data. Specifically, the underestimation of surface albedo from MERRA when the snow is missed results in an underestimation of POA irradiance (dotted line) in the morning and afternoon when the high albedo of snow impacts the radiation reaching the POA measurements. Using the correct surface albedo (solid line) removes the error.

\section{CONCLUSIONS}

This study diagnoses the uncertainty of the transposition models simulating solar radiation on inclined surfaces. A computer model is used to imitate isotropic diffuse radiation in space and numerically compute the POA irradiance. A comparison of the isotropic models, LJ1963 and BA2002, suggests BA2002 substantially underestimates diffuse POA irradiance when diffuse radiation is perfectly isotropic. The underestimation is more pronounced for low surface albedo. The uncertainty in the transposition models is also evaluated using surface observations. Surface measurements of solar radiation on horizontal surfaces are used as inputs to an is otropic model, LJ1961, and an empirical model, PEREZ, to compute POA irradiances and compare them to those measured by the 1-axis CMP 11 and IMT. Our results indicate that the use of empirical coefficients in the PEREZ model may lead to significantly different uncertainties in simulations of POA irradiance. In addition, using more accurate surface albedo data can reduce the uncertainty of the POA irradiance, especially in winter. This study can be used as a guide to develop physics-based models and better evaluate PV solar panel performance.

\section{ACKNOWLEDGEMENTS}

This work was supported by the U.S. Department of Energy under Contract No. DE-AC36-08GO28308 with the National Renewable Energy Laboratory. Funding provided by Solar Energy Technologies Office. The U.S. Government retains and the publisher, by accepting the article for publication, acknowledges that the U.S. Government retains a nonexclusive, paid-up, irrevocable, worldwide license to publish or reproduce the published form of this work, or allow others to do so, for U.S. Government purposes.

\section{REFERENCES}

[1] G. M. Stokes and S. E. Schwartz, "The Atmospheric Radiation Measurement (ARM) Program: Programmatic background and design of the cloud and radiation test bed," Bull. Amer. Meteor. Soc., vol. 75, pp. 1201-1221, 1994.

[2] M. Sengupta, A. Habte, P. Gotseff, A. Weekley, A. Lopez, C. Molling, and A. Heidinger, "A physics-based GOES product for use in NREL's National Solar Radiation Database," European Photovoltaic Solar Energy Conference and Exhibition, vol. Amsterdam, Netherlands, 2014.

[3] Y. Xie, M. Sengupta, and J. Dudhia, "A Fast All-sky Radiation Model for Solar applications (FARMS): Algorithm and performance evaluation," Sol. Energy, vol. 135, pp. 435445, 2016.

[4] R. Perez, P. Ineichen, R. Seals, and J. Michalsky, "Modeling daylight availability and irradiance components from direct and global irradiance," Sol. Energy, vol. 44, pp. 271-289, 1990.

[5] C. Gueymard, "An anisotropic solar irradiance model for tilted surfaces and its comparis on with selected engineering algorithms," Sol. Energy, vol. 38, pp. 367-386, 1987.

[6] D. Reindl, W. Beckman, and J. Duffie, "Evaluation of hourly tilted surface radiation models," Sol. Energy, vol. 45, pp. 9-17, 1990.

[7] B. Liu and R. Jordan, "Daily insolation on surfaces tilted towards the equator," ASHRAE Journal, vol. 3, pp. 53-59, 1961.

[8] V. Badescu, "3D isotropic approximation for solar diffuse irradiance on tilted surfaces," Renewable Energy, vol. 26, pp. 221-223, 2002.

[9] Y. Xie, "Study of ice cloud properties from synergetic use of satellite observations and modeling capabilities," Ph. D., Department of Atmospheric Sciences, Texas A\&M University, College Station, TX, 2010.

[10] Y. Xie, P. Yang, G. W. Kattawar, P. Minnis, Y. X. Hu, and D. Wu, "Determination of ice cloud models using MODIS and MISR data," Int. Remote Sens., vol. 33, pp. 4219-4253, 2012.

[11] Y. Xie, P. Yang, G. W. Kattawar, B. Baum, and Y. X. Hu, "Simulation of the optical properties of ice particle aggregates for application to remote sensing of cirrus clouds," Appl. Opt., vol. 50, pp. 1065-1081, 2011.

[12] Y. Xie, P. Yang, G. W. Kattawar, P. Minnis, and Y. X. Hu, "Effect of the inhomogeneity of ice crystals on retrieving ice cloud optical thickness and effective particle size," J. Geophys. Res., vol. 114, pp. D11203, doi:10.1029/2008JD011216, Jun 5 2009.

[13] P. Loutzenhiser, H. Manz, C. Felsmann, P. Strachan, T. Frank, and G. Maxwell, "Empirical validation of models to compute solar irradiance on inclined surfaces for buiding energy simulation," Sol. Energy, vol. 81, pp. 254-267, 2007.

[14] M. Rienecker, M. Suarez, R. Gelaro, R. Todling, J. Bacmeister, E. Liu, M. Bosilovich, S. Schubert, L. Takacs, G. K. Kim, S. Bloom, J. Chen, D. Collins, A. Conaty, A. Da Silva, W. Gu, J. Joiner, R. Koster, R. Lucchesi, A. Molod, T. Owens, S. Pawson, P. Pegion, C. Redder, R. Reichle, F. Robertson, A. Ruddick, M. Sienkiewicz, and J. Woollen, "MERRA: NASA's Modern-Era Retrospective Analysis for Research and Applications," J. Climate, vol. 24, pp. 3624-3648, Jul 2011. 